\title{
Environmental enrichment for primates in laboratories
}

\author{
H. M. Buchanan-Smith \\ Behaviour and Evolution Research Group, Psychology, School of Natural Sciences, University of Stirling, \\ Stirling FK9 4LA, Scotland
}

Received: 1 October 2010 - Revised: 12 April 2011 - Accepted: 13 April 2011 - Published: 14 June 2011

\begin{abstract}
Environmental enrichment is a critical component of Refinement, one of the 3Rs underlying humane experimentation on animals. In this paper I discuss why primates housed in laboratories, which often have constraints of space and study protocols, are a special case for enrichment. I outline a framework for categorising the different types of enrichment, using the marmoset as a case study, and summarise the methods used to determine what animals want/prefer. I briefly review the arguments that enrichment does not negatively affect experimental outcomes. Finally I focus on complexity and novelty, choice and control, the underlying features of enrichment that makes it successful, and how combined with a thorough understanding of natural history we can put effective enrichment into practice in laboratories. Throughout the paper I emphasise the need to evaluate enrichment to ensure it is having the desired effect.
\end{abstract}

\section{Introduction}

I once read a student essay that said "There are many research papers that can be used to enrich primates". This tickled me no end. Papers are actually a very good way to enrich primates because the primates can destroy them - they can be ripped up, food can be hidden between the pages, scent can be added, the primates might add them to their bedding material, and paper changes texture in water!! Unfortunately they may block drains and one has to be aware of safety concerns (e.g., staples removed, and non-toxic ink etc.). Of course what the student had meant was that there is a vast literature on different types of enrichment that have been used to promote the welfare of primates.

So what can I add to this literature? My intention in this paper is to focus on providing enrichment for primates in a laboratory environment, which has different constraints than zoos which has received more attention in the enrichment literature. Compared with zoos, enclosures in most laboratories are smaller, often with no outdoor access, have the constraints of study protocols and the research subjects housed within them are often subjected to procedures that have the potential to cause pain, suffering, distress or lasting harm. To tackle this topic of enrichment for primates in the laboratory, first, I shall define environmental enrichment, and then summarise why primates may be special candidates for

Correspondence to:

H. M. Buchanan-Smith

(h.m.buchanan-smith@stir.ac.uk) enrichment. I shall provide a framework for categorising the different types of enrichment, with a focus on laboratory settings, providing specific examples for marmosets. I shall summarise the methods used to determine what animals want/prefer, and argue that in most cases enrichment does not negatively affect experimental outcomes. Finally I shall focus on the underlying features of the enrichment that makes it successful, and how we can put these into practice in laboratories. The need to evaluate enrichment, and environmental and husbandry changes to ensure they are having the desired effect, is emphasised throughout.

Use of primates in laboratory research and testing, and enrichment resources

The main species of primate bred and used in laboratories for research and testing will be the focus here, namely chimpanzees (Pan troglodytes, still used in USA), rhesus macaques (Macaca mulatta), cynomolgus macaques (Macaca fascicularis), common marmosets (Callithrix jacchus) and tamarins (Saguinus spp.). Chapters in the UFAW Handbook edited by Hubrecht and Kirkwood (2010) provide excellent up-to-date accounts on all these primates, and Young's (2003) book on "Environmental Enrichment" is still, in my view, the best source to read on the topic. The Shape of Enrichment website (http://www.enrichment. org/) provides a range of very useful and practical information including the process of planning enrichment, a safety database, details of workshops and publications, and has a library of enrichment videos to loan. Publications on 
Table 1. Behaviours that may indicate poor welfare in primates (NB: not all behaviours are applicable to all species). Adapted from JWGR (2009).

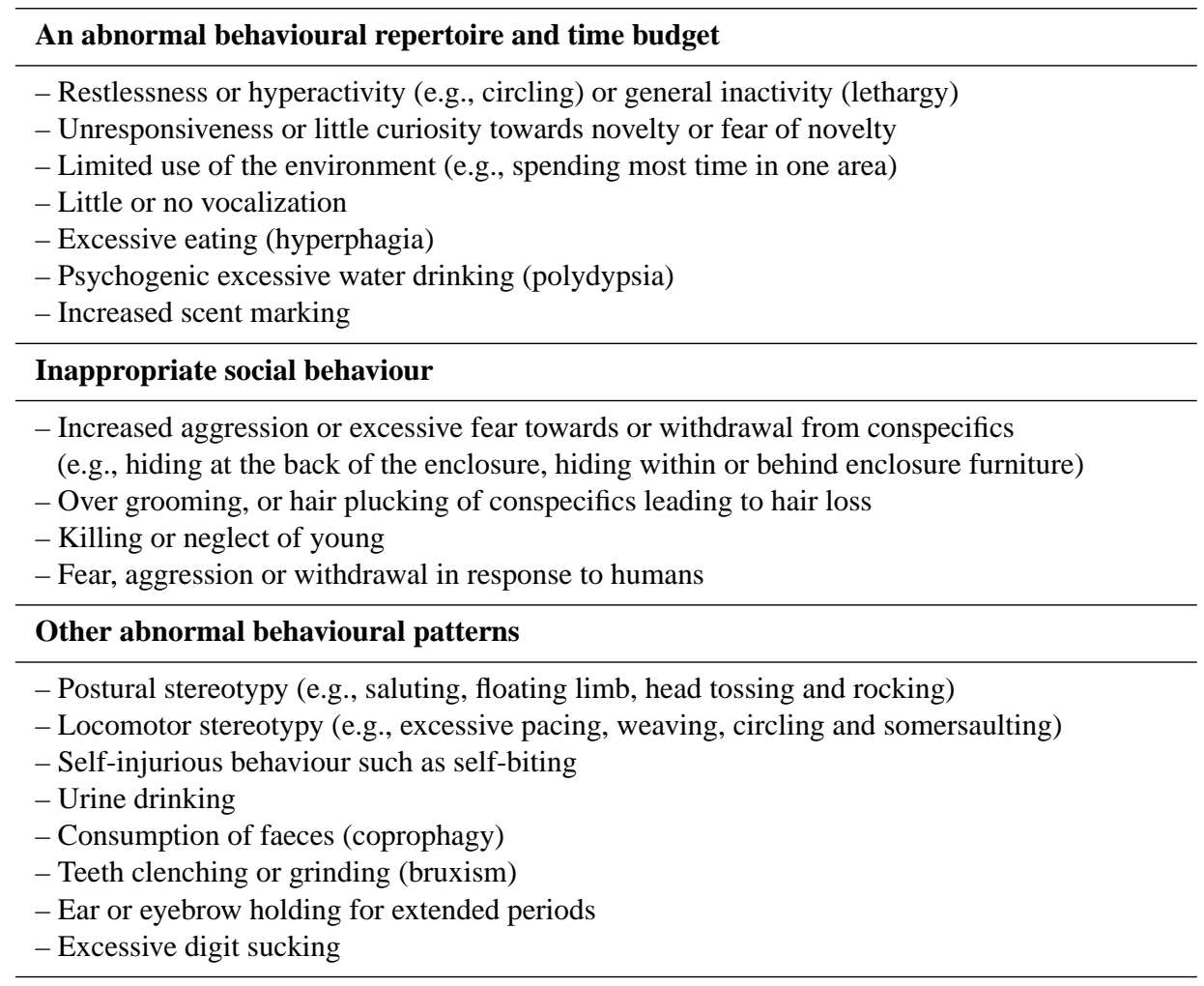

enrichment can be searched on the Animal Welfare Institute's Primate Enrichment Database (http://labanimals.awionline. org/SearchResultsSite/enrich.aspx).

\section{The definitions and categories of environmental enrichment}

\subsection{Definitions}

In 1925, Robert Yerkes wrote "The greatest possibility for improvement in our provision for captive primates lies with the invention and installation of apparatus, which can be used for play or work" (cited in Shepherdson 1998, p. 7). Some twenty five years later Hediger (1950) wrote the book "Wild animals in captivity" addressing many of the issues that are still pertinent today, such as the problem of confined space, the quality of the environment in relation to the natural adaptations, quantity and quality of food in relation to method of delivery and timing, and the animals' relationship with humans. Although the term environmental enrichment had not been coined back then, these authors were pioneers in paving the way for a burgeoning discipline which addresses how to promote the welfare of animals in captivity.

There have been numerous definitions of environmental enrichment. Shepherdson (1998), co-editor of the book "Sec- ond Nature", described environment enrichment as "an animal behavior principle that seeks to enhance the quality of captive animal care by identifying and providing the environmental stimuli necessary for optimal psychological and physiological well-being." (p. 1). The Enrichment Working Group of the Behavior and Husbandry Advisory Group (BHAG), a scientific advisory group of the American Zoo and Aquarium Association, defines enrichment as " $a d y$ namic process in which changes to structures and husbandry practices are made with the goal of increasing behavioral choices available to animals and drawing out their speciesappropriate behaviors and abilities, thus enhancing animal welfare" (BHAG, 1999). What these definitions have in common (as do the many others, e.g., Newberry, 1995) is the ultimate goal of enhancing animal welfare.

Indeed enrichment is a part of the Refinement $\mathrm{R}$ of the 3Rs, Replacement, Reduction and Refinement (Russell and Burch, 1959), which underlie humane experimental technique and are now enshrined in legislation of many countries (e.g., European Directive and UK Home office). Refinement is defined as: "Any approach which avoids or minimises the actual or potential pain, distress and other adverse effects experienced at any time during the life of the animals involved and which enhances their well-being" 


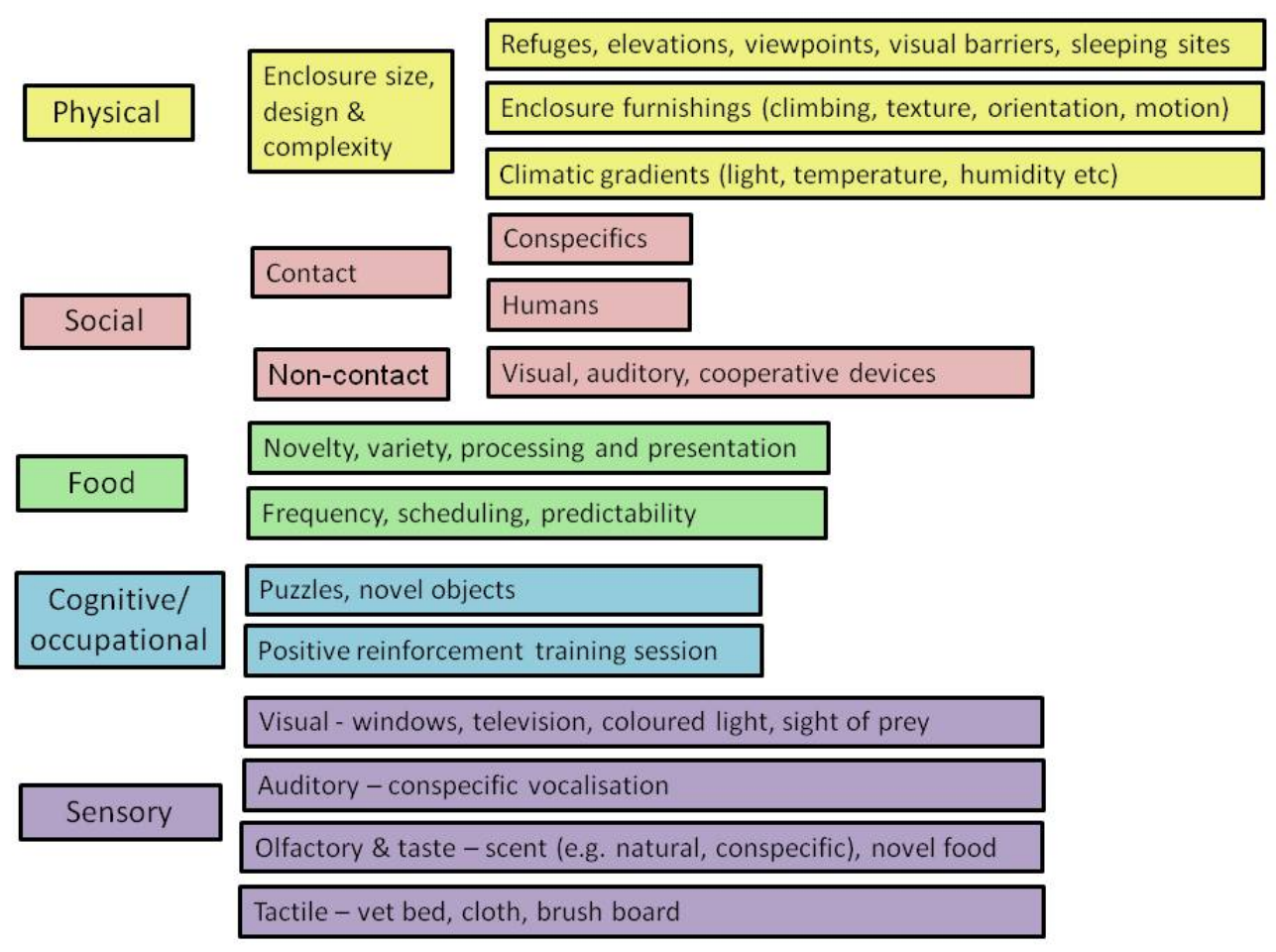

Figure 1. The categories of environmental enrichment for primates in laboratories (adapted from Bloomsmith et al. (1991) and The Shape of Enrichment website).

(Buchanan-Smith et al., 2005, p. 379-380). Enrichment - enhancing well-being - is at the centre of Refinement, although given the context of Refinement in laboratories, there is also a focus on avoiding or alleviating negative consequences as a result of conducting scientific procedures.

Animal well-being/welfare however, is a multidimensional construct, which we have difficulties in measuring! Welfare lies along a continuum from bad/poor to good. Bad/Poor welfare may be characterisied by a restricted behavioural repertoire, an abnormal time budget, inappropriate social behaviour, increased aggression to conspecifics and other abnormal behavioural patterns (JWGR, 2009 and see Table 1). Indicators of good welfare include the primates appearing to be relaxed, inquisitive, having a diverse behavioural repertoire, and spending time in affiliative allogrooming, body contact and play or foraging (JWGR, 2009). Dawkins (2004) simplifies animal welfare into two questions "Are the animals healthy?" and "Do they have what they want?". Whilst improving welfare is the ultimate purpose of enrichment, it is usually broken down into specific goals (see Sect. 3) but first we must consider the range of enrichment possible.

\subsection{Categories of environmental enrichment}

For enrichment to be successful it must be holistic. It is helpful to think of enrichment in categories - physical, social, food, cognitive and sensory - to ensure that all aspects of a primate are being considered in relation to his or her natural adaptations. Figure 1 outlines these five different types of enrichment, which are not mutually exclusive. Within this categorisation the key concepts of enrichment are introduced: complexity and novelty, choice, and control (and their relationship to predictability, see Sect. 6). It is helpful in planning any enrichment programme to consider what can be done to improve each category. It is critical to remember that what may improve the welfare of an individual may not be appropriate for another - care staff must get to know individuals, and the provision of choice is vital for group-housed primates.

\section{Goals of enrichment}

Whilst definitions of environmental enrichment are needed to ensure we know what we are talking about, it is better to break down enrichment into more specific, and more measurable goals, which should be assessed. If the overarching purpose of improving welfare is not met, the enrichment attempt has been unsuccessful. The underpinning goals of enrichment depend upon how specific (e.g., a feeding device, or 
the addition of new shelves) or broad (e.g., move to a larger more complex enclosure, introduction of a human socialisation programme) the changes are. None-the-less the following list, adapted from Young (2003) is imperative to focus on what enrichment is designed to achieve, and to consider how to measure its success. As with the different categories of enrichment, these goals are not mutually exclusive.

\section{i. Increase diversity and performance of normal (wild, desired) behaviours}

In many captive environments especially in laboratories, the primate is restricted, physically and socially such that its behavioural repertoire becomes limited. Without opportunities and/or the appropriate external stimulation to engage in certain behaviours, and without the perception of control such that actions may result in change, then animals can become listless, unexplorative, disengaged, and their days may be limited to basic functions. They become bored. The provision of more complex, dynamic physical and social environments, with elements of responsivity, and by providing more choice, will give the primates this perception of control. Making some positive events less predictable (e.g., feeding), and providing novelty will prevent or reduce boredom.

The term "normal" is used in the above goal, with the bracketed description that "wild, desired" is what is meant. In fact, deciding what is normal is extremely difficult for captive primates, which are not domesticated nor are traits intentionally bred specifcially for laboratories in a similar way as strains of rats or mice. Certainly for primates, an understanding of natural behaviour is critical, in relation to how the primate has adapted to its ecological niche (e.g., locomotion, posture, foraging, nutritional requirements, food processing, hiding from threats/predators, breeding and interacting with conspecifics etc.). But care must be exercised as it is unlikely to be desirable to get captive primates to exhibit wild-type activity budgets given that their captive environments are so different (Shepherdson, 1998; Veasey et al., 1996). In any case, there are few data giving definitive wild activity budgets for a given species as they vary across habitats, there are often observational difficulties, small sample sizes, and genetic differences. The approach assumes also that wild animals have sufficient welfare, which is not always the case, as wild animals may be preyed upon, injured, diseased or suffer malnutrition and receive no veterinary care! Most critically captive animals adapt to their environment, but this behavioural change is not necessarily indicative of decreased welfare.

Quantifying whether this goal has been achieved is relatively easy - as it focuses on behaviour alone, and the researcher can draw up a list of behaviours they wish to see increase, and compare the frequency and/or duration before and after enrichment. The methods and welfare consequences of increasing behavioural diversity must be carefully assessed. It may be natural, and indeed desirable, to allow primates to mob an object they perceive to be threatening, or to be cautious of a novel object or feeding device, thus increasing locomotor behaviour. What is critical in these instances is that the primate has perceived control, that he or she is able to remove them self from the situation and approach in their own time.

\section{ii. Increase positive utilisation of the environment}

Many captive primates do not fully utilise the enclosures provided. For example, marmosets and tamarins are often reluctant to utilise the lower halves of their enclosures (e.g., Prescott and Buchanan-Smith, 2004); marmosets may spend the majority of their time in "verandas" or "turrets" which affords them a better view of the surroundings, or macaques may be so fearful that they spend much of their day at the highest point at the back of the enclosure. Any effort to increase utilisation of the environment must be done with a thorough assessment of what is limiting the primates' use of the full environment - for example fear (e.g. threats from group mates, neighbours or care staff), or a lack of interest in that enclosure part (as poorly furnished, poor view, etc.). Given the comparatively small size of laboratory enclosures, ensuring all parts are used is important (Buchanan-Smith et al., 2004), although it must be accepted that certain parts are preferred, and making such preferred parts less desirable to encourage utilisation of other parts is not an enrichment solution! Instead enrichment should aim to enhance the attractiveness of the under-utilised areas, whilst accepting that there are always going to be preferred areas. It is also important to note there may be circadian rhythms in patterns of use.

For primates in laboratory enclosures, understanding what the primates are doing when you are not present is critical, and the use of cameras may assist you in determining whether your presence is a significant factor in where the primates spend their time, and indeed how they behave. Your presence may influence the primates such they spend all their time at the top front (or back) of the enclosure, being vigilant, and when the laboratory is quiet they may engage in a broader range of social and other desirable behaviour patterns and more fully utilise the enclosure as there are no external noises or humans, which may provide (often unreliable) signals as to events, to attract their attention.

\section{iii. Prevent abnormal behaviour developing}

This third goal is proactive, and not reactive. Of course, if abnormal behaviours are already present then the goal is to reduce their frequency and/or diversity, and the reduction is measurable. Preventing abnormal behaviours 
focuses on promoting good welfare and positive emotions. We should be beyond attempts to repairing, or limiting the damage, and proactively be providing a life worth living. That said, it is important to know your primates well enough that you know when they are "out of sorts", and can respond before the very first signs of any abnormal behaviour patterns arise. Permanently removing ingrained abnormal stereotypic behaviours is rare so prevention is far better than cure. Again to achieve such a goal it is critical to understand and avoid the triggers for display of abnormal behaviours in relation to presence of key individuals, or certain events (such as feeding, cleaning, time of day etc.).

There are a number of factors that increase the likelihood of abnormal behaviours developing including maternal factors, early rearing environment, single housing, handling and restraint. Even before the primate is born, if the mother is stressed the infant has a higher predisposition to develop abnormal behaviour. For example, Schneider et al. (1999) socially isolated pregnant rhesus macaques for $10 \mathrm{~min}$, five times week in darkened room with random noise. In the short term this caused decreased infant weight, poorer attention and neuromotor maturity (e.g. slower development of coordinated movement, response speed etc.) compared to controls. Longer terms effects included social deficits (e.g. inappropriate interactions with conspecifics), increased abnormal behaviour and responsivity to stressors. Early deprivation leads to increased likelihood of stereotypical and self injurious behaviours developing as well as depression and an inability to cope with adversity. It also impacts negatively on the animals' physiology, and its reaction to stress (e.g. a heightened acute response and longer term lower cortisol levels) and immune function (reviewed in Pryce et al., 2005; Sanchez, 2006; Suomi, 1997) thereby limiting the primates' ability to fight disease.

A large survey of laboratory-housed rhesus macaques reported that $89 \%(n=362)$ of rhesus macaques show at least one abnormal behaviour (Lutz et al., 2003). Logistic regressions on a smaller sample of 239 macaques, showed that high risk factors in the development and maintenance of these abnormal behaviours were: individual housing at "an early age", longer time spent individually housed, greater number of blood draws and location changes, and if the macaques were nursery reared (with other young macaques), as opposed to motherreared. They also noted that males showed a greater predisposition to abnormal behaviours with self injurious behaviours being 8-9 times higher. Therefore enrichment must occur at every stage of the life of a primate, destined for use in the laboratory, as these early life experiences have long-lasting consequences. Good early rearing and life experiences will lead to increased resilience to face the challenges of the laboratory environment and testing protocol. Even if early maternal separation has occurred, enrichment may still be beneficial. In rats, enrichment during the peripubertal period completely reversed the effects of maternal separation on both the hypothalamic-pituitary-adrenal and behavioural responses to stress (Francis et al., 2002). If the primates are not bred in-house, it is recommended that breeding facilities and laboratories work closely together to ensure the primates are not predisposed to developing abnormal behaviours on study. Once on study, increasing the signalled predictability of negative events is desirable (reviewed in Bassett and Buchanan-Smith, 2007), as well as providing appropriate compatible individuals for social support (e.g., Schaffner and Smith, 2005), and a stimulating environment which actively engages individuals.

\section{iv. Increase the ability to cope with challenges in a more normal way}

Primates in captivity, and indeed more so in laboratories than most other captive environments, are faced with numerous challenges. Primates in laboratories may be captured on a regular basis for handling, weighing and dosing; the stability of their groups may be regularly altered as individuals are moved onto study, and aspects of their physical and social environment may be manipulated for scientific purposes. As noted above, the importance of the early rearing environment must not be underestimated in the development of primates into resilient adults. Furthermore, as many challenges in the environment involve humans (for capture, dosing etc.), good human socialisation and a positive reinforcement programme is likely to be a very effective form of enrichment (e.g., Bassett et al., 2003).

There are several ways you can measure whether such enrichment has been successful in increasing coping capacity. If physiological measures are being taken then there may be decreases in cortisol baseline and response, heart rate or blood pressure. Signs of fear (such as fear grimacing, or vocalisation) may decrease, and the time taken for behaviour to return to normal after the stressful event will also decline.

Whilst it is critical that enrichment is designed so that it is goal driven, once again it is important to emphasise that not all of the goals outlined above may be achieved simultaneously. The means of achieving the goals should be carefully considered, and individual differences must be taken into account. As we shall see below, although it is easier to assess one change at a time in an individual's environment, enrichment plans should be holistic and address the complexities of primates' cognitive and social needs. 


\section{Are primates special candidates for enrichment?}

All animals need special consideration for enrichment, but in this section I shall outline some characteristics of primates that make them challenging (and exciting!) to enrich. Like other animals, understanding the primate's biology and behaviour underpins successful implementation of environmental enrichment.

On a general level, primate brains are larger (in relation to body size) than other mammals used in laboratories, and they are considered to be cognitively more complex (e.g., Dunbar and Schultz, 2007). Bigger brains and complex cognition does not necessarily in itself mean that they can suffer more (see Mendl and Paul, 2004). Bekoff (2002) stated that suffering may be as great in an individual which experiences "this is painful" as one which is consciously aware and "feels pain". Indeed Broom (2010) has argued that more cognitively complex individuals may actually help them to cope with adverse conditions and therefore not suffer as much as a less cognitively complex individual. None-the-less, cognitively complex individuals such as great apes, may also be able to empathise with the suffering of others, and dread future events increasing their own ability to suffer (Mendl and Paul, 2004; Smith and Boyd, 2002). Primates certainly experience pain and negative as well as positive emotions, but this does not set them apart from other mammals used in laboratories although Broom (2010) suggests that more complex brains may allow for more possibilities of pleasure. These arguments are not fully evaluated in relation to good welfare and suffering but may suggest that primates are indeed a special case. What sets them apart, I would argue, is the intricacy of adverse effects resulting from inappropriate rearing and that their larger brains have evolved for dealing with the complexity of social and physical world. Providing appropriate rearing and such complexities in the laboratory environment can be very challenging, given the constraints of laboratory life, and the study requirements. As a result, primates can suffer from boredom and fear, and the consequences of this, and inadequate rearing histories and environments can lead to poor welfare.

As already noted one of the greatest influences on an animal's development and resilience/coping ability as an adult, is his or her early rearing environment. Although some primates are bred and subsequently used as research subjects in the same laboratory, many are bred in special centres (often overseas), and the laboratory of end-use does not have direct control over for example, social groups, weaning age, and conditions (although many countries have legislation to cover designated breeding centres). Primates are also very longlived compared with other laboratory animals which poses challenges for care staff to provide for good welfare throughout their lives, and as their needs change. Waitt et al. (2010) provide a list of considerations for designing environments for aged primates that includes accessibility issues, positioning, size and type of furnishings, to avoid poor welfare re- lated to age-related arthritis, deteriorating vision, difficulties in thermoregulation etc. Younger individuals too require special provisioning to allow them to engage more in play, to explore and to learn contingency between behaviours and their outcome. For example, it is known that having control over aspects of the environment improves the welfare of younger, more than older, individuals (Badihi, 2006).

In summary, whilst the evolutionary closeness to ourselves, and potential for greater suffering, and potentially also for pleasure, are good reasons why primates are special cases, I feel the strongest argument is the need to challenge the large brains, designed to deal with social and physical complexity in their worlds. Enrichment can, and must, directly address this.

\section{Knowing what primates want, and whether getting what they want benefits them}

There are many arguments as to why we should provide enrichment for primates - the first being an ethical responsibility to animals in our care. As primates in laboratories are used primarily for the benefit of humans (e.g., in toxicology and safety evaluations, applied studies for human and veterinary medicine and fundamental studies; Rennie and Buchanan-Smith, 2005), it is our duty to ensure that they suffer the least, and we proactively try to improve their welfare so they lead the best lives they can within the constraints of the laboratory environment and study protocol. To do this we need to know what they want enrichment-wise, and we need evidence that enrichment benefits them.

\subsection{The benefits of enrichment}

As the overarching goal of enrichment is that it improves welfare, it should come as little surprise that there is a wealth of evidence to prove that it can and does! (e.g., see Primate Enrichment Database, Young, 2003). There are numerous examples of the goals outlined above (see Sect. 3) being met - through the measurement of behaviour. As behaviour is, as Dawkins (2004, p. S4) put it "the result of all of the animal's own decision-making processes" it is hardly surprising that the underlying physiology, immunology, neurology is also changed by enrichment, as this impacts on behaviour and health. Enrichment has been show to reduce the so-called stress hormone, cortisol, and to improve the immune response (Schapiro et al., 1993, 2000), and to result in desirable body mass gain without a comparative increase in food consumption (Schapiro and Kessel, 1993). There is evidence in many non-primate species that enrichment also positively impacts brain cell density, increase brain plasticity, improves speed and recovery from brain damage, and enhances memory and other cognitive process (reviewed in Young, 2003), and a wealth of literature in human and non-human primates emphasising the importance of 
"enriched" environments on infant development (e.g., Ventura and Buchanan-Smith, 2003).

\subsection{Determining which enrichment to give primates}

Let us return to Dawkins' (2004) argument that animals with good welfare are healthy and have what they want. Health is measured by a battery of measures which include physical factors (e.g., growth, body condition), immune and autonomic parameters (e.g., temperature, heart rate, blood pressure), neuroendocrinology (e.g., cortisol, adrenaline), as well as reproduction and lifespan. But how can we determine exactly what primates want - and how much they like it? The amount of time a primate engages with a specific enrichment device, how it engages with it behaviourally and vocally or where animals position themselves spatially in relation to the environment are simple enough to measure and give a good indication of their preferences. There are however, more sophisticated techniques to determine how much an animal likes the enrichment, which have great value, but also have some limitations in interpretation. Dawkins (2004) and the FELASA (2006) working group document summarise a number of techniques to determine how we can tell what animals like and want. Such techniques include preference/choice tests, consumer demand studies, and anticipatory behaviours towards enrichment.

Choice/preference tests for example, which may give an animal a choice among different types of enrichment, may tell us which they like the best of the choices offered. Knowing what to offer the primates in the first instance should be based on a good understanding of their natural history (see Sect. 7). Even if choices offered are appropriate, such preference tests cannot inform us of the strength of the choice, and their choices may not be independent of the set of options available in the test (Bateson, 2004). Furthermore such tests do not inform us of the underlying motivation. The choice an animal makes may be a result of the animal's motivation to minimize deprivation, to maximise pleasure, or to monitor potential risk (Hubrecht, 2010). Furthermore, if the majority of animals choose one sort of enrichment this does not mean that it should be given exclusively - individual preferences exist, and hence choice must be maintained.

Another approach is consumer demand, where for example, the primate has to indicate the strength of their motivation by paying for it (e.g. by pushing a weighted door to get access to it, see Cooper and Mason, 2000). This approach also has some problems as the demand curves derived may not accurately reflect the value of their choice (Cooper and Mason, 2001). It is also known that the preferences of animals and willingness to pay for resources will be influenced by, for example, their stage of development, sex, temperament, and past experience (Bateson, 2004).

Animals use signals to predict events, and anticipatory behaviour seen prior to a known event has also been used to assess the rewarding properties of environmental enrichment in a variety of non-primate species (e.g., Hansen and Jeppesen, 2006; Spruijt et al., 2001; van der Harst et al., 2003, 2005). Anticipatory behaviour can be useful as it tells us how excited the primates get when they know something good will happen, with the strength of their excitement indicating how much they are looking forward to it. In some preliminary research with common marmosets (Badihi and BuchananSmith, 2005), six pairs of marmosets were studied in each of three events (stimuli) known to be positive (marshmallow), neutral (primate chow) and mildly negative ( $2 \mathrm{~s}$ of hairdryer blast) to the marmosets. Pavlovian conditioning (pairing the stimuli with the signal) was used so the marmosets learnt the signal that announced each oncoming stimulus. The monkeys behaved differently in the anticipation phase between the signal and the occurrence of the forthcoming positive event compared with the neutral and negative events. For example, the marmosets spent more time eagerly awaiting the positive stimuli - compared with the neutral and aversive stimuli they spent more time in agitated locomotion, hanging at the cage front and watching the observer when they knew something positive was coming. These studies indicate that anticipatory behaviour is a useful method for assessing the value of environmental enrichment for monkeys.

The critical point to re-emphasise is that choice must be maintained. Once tests have determined what animals want, and what choices are best offered, the opportuity to choose must continue. Individual preferences, hierarchical status, time of day, current health are all factors that may influence your choice. This, combined with the arguments that having choice is important, are all reasons why offering choices should be a part of the routine.

\subsection{Enrichment and experimental outcomes}

Within laboratories, there is an additional concern that enrichment may have unwanted effects on experimental outcomes (Benefiel et al., 2005). As I have argued above, that enrichment has an impact on underlying brain structures and can alter physiology, and the immune response, does indeed suggest that experimental outcomes may be different (reviewed in Sherwin, 2004 and Hubrecht, 2010) although no research has explored this specifically in primates. Most of the arguments come from researchers who are concerned that their science will be adversely affected. Below I refute three common arguments why enrichment cannot be used.

The first argument against enrichment is that it may bias results, as enriched animals will produce different results from those living in unenriched environments. But if we turn this concept on its head, primates living in barren, understimulating environments that lead to stress and abnormal conditions will adversely affect studies that are designed to be conducted on normal animals. The normal, evolved state is one of enrichment, and as Würbel (2000) and Garner (2005) argue, animals raised and living in enriched environments should be better (not worse) models, and the results 
from such animals should have improved external validity. Enrichment should improve data from experiments designed for normal healthy animals.

A second argument is that enrichment may influence the variability of the results as between-subject variability increases; such increases in variability can lead to reduced sensitivity and hence a larger sample size required to achieve statistical significance. This opposes Reduction, one of the 3Rs. There are some reports of enrichment increasing, decreasing or having no effect on variation (e.g., Eskola et al., 1999 for rats; van de Weerd, 2002, for no effect on variation in mice). In some cases, scientific output (such as heart rate in restrained marmosets) may be at ceiling effects for highly stressed animals, and improving welfare will increase variation, through more relaxed monkeys. Again, rather than using the argument of enrichment potentially increasing variation as a reason for not enriching primates, concern should be given to the reason the primates are being tested, and whether external validity is important, as it will be in most cases. If the results are only applicable to and replicable in a certain unenriched population, then their value will be limited. If the results come from highly stressed animals and are at a ceiling level, their validity to a normal population can be questioned.

This leads us to the third and final point that enrichment may reduce replicability across laboratories, and across time. That enrichment reduces replicability across time or laboratories has no good evidence to support it, as even when conditions are rigorously standardised across laboratories, the results from mice still differ significantly (Crabbe et al., 1999). My overall conclusion is that enrichment should be used, but there is a need for case-by-case study in determining which enrichment may be used without adverse effects on experimental outcomes or sample sizes. Indeed, enrichment, and improved welfare may lead to an increase in the amount of experimental data that can be collected, and the data will, in most cases, be of higher quality.

\subsection{Evaluation of enrichment and potential adverse effects}

Evaluating any changes made to the environment is critical to ensure that enrichment is really effective (i.e. improves welfare), and does not have adverse effects on the animal's welfare or experimental outcomes. Unfortunately some enrichment may have undesirable effects, such as increases in aggression (e.g., Erwin, 1979; Honess and Marin, 2006), or other adverse effects such as increasing stress, injury disease and infection through access to outdoor areas or if the enrichment acts as a vector for disease transmission, or adversely affects nutritional balance (Etheridge and O'Malley, 1996; Hahn et al., 2000; Murchison, 1993; and see Baer, 1998 for an excellent review). In many cases, such adverse effects go unreported, but The Shape of Enrichment website provides a Safety Database with vital information (in an anonymous form) and can be searched by several criteria. The success of the database relies on your contributions, so do use the database to inform your own enrichment efforts and to share your experiences to help to avoid potential suffering of animals.

Ensuring that there are no serious adverse effects of enrichment is one reason why evaluation is so critical. Another reason is to provide evidence of its beneficial effect. Whilst enrichment need not cost a great deal of money, it often needs some, and may involve changes of routines. Having good evidence to show laboratory managers that the enrichment has worked, will likely increase the chances of receiving further funding and motivation for such positive changes. Any financial investment is often offset by improvements in welfare, and subsequent reduction in animal management and veterinary bills. Some staff, set in their routines, are often reluctant to get involved with enrichment arguing it is too time consuming, but enrichment can become a part of the routine, built into the standard operating procedures, and not as is sometimes seen, an add on when there is time left over. In nearly all cases, the benefits of using enrichment outweigh potential negative effects, if all precautions are taken to minimise potential adverse outcomes, and the enrichment programme is well planned and involves team work.

\section{What concepts underlie successful enrichment?}

I have categorised enrichment into five different types (Fig. 1), but the underlying themes, are concepts that relate to the biological functioning of mammals. These concepts are complexity and novelty, choice, and control (and their relationship to predictability). They relate well to Poole's (1998) basic needs of mammals which are security (a safe area in which to rest and feel secure), complexity, achievement (control), and novelty (to satisfy curiosity and prevent boredom). Specific examples of how to use the enrichment categories, and achieve the goals, through consideration of the underlying concepts are given using marmosets as a case study in Table 2. In planning any enrichment programme, such a table might be drawn up for the specific species in question, and once a programme is in place and agreed upon by the whole team, rotas developed so there is a clear line of expectation.

\subsection{Complexity and novelty}

Almost all attempts at environmental enrichment introduce additional complexity. The complexity of the captive environment includes several dimensions: the physical structure of the enclosure, the presence of other individuals, the presence of manipulable objects (Sambrook and BuchananSmith, 1997). Novelty adds to the complexity of an environment and as information gathering about relevant aspects of one's world is a critical part of daily life, novelty provides such opportunities to explore and learn. Although it 
Table 2. Examples of applying the different enrichment categories (see Fig. 1) to common marmosets. Note that all examples include increasing complexity, and hence choice, as an enrichment goal.

\begin{tabular}{|c|c|c|c|}
\hline $\begin{array}{l}\text { Enrichment } \\
\text { category }\end{array}$ & Subcategory & Specific example for marmosets & Enrichment goals, concepts and behavioural opportunity \\
\hline \multirow[t]{13}{*}{ Physical } & \multirow[t]{13}{*}{$\begin{array}{l}\text { Enclosure size, design and } \\
\text { complexity }\end{array}$} & $\begin{array}{l}\text { Adequate size to allow to appropriate group size, and } \\
\text { furnishings to promote quadrupedal locomotion, and } \\
\text { clinging and leaping, and height above humans. }\end{array}$ & $\begin{array}{l}\text { Expression of normal social behaviour, locomotor behaviour, and security (perceived } \\
\text { control) with height; full use of the space. }\end{array}$ \\
\hline & & Turrets and verandas. & $\begin{array}{l}\text { Improved visual stimulation with } 360^{\circ} \text { viewpoint in turret, satisfying curiosity, } \\
\text { increasing predictability of husbandry events. }\end{array}$ \\
\hline & & $\begin{array}{l}\text { Visual barriers such as hanging screen, and rubber } \\
\text { matting (to which marmosets can cling) and refuges. }\end{array}$ & $\begin{array}{l}\text { Perceived control over visual access to cage mates and room mates; unpredictable } \\
\text { movement of screen; opportunities for play (e.g. hide and seek, ambushing). }\end{array}$ \\
\hline & & Outside runs or exercise rooms, connected by ducting. & $\begin{array}{l}\text { Opportunities to engage in wider range of normal behaviours through increased space, } \\
\text { insect capture, and experience of wider range of climatic gradients if outdoors. Rotation } \\
\text { increases novelty, and may introduce new odours, and stimulate senses. }\end{array}$ \\
\hline & & $\begin{array}{l}\text { Windows to give visual access to outdoors, } \\
\text { care staff areas etc. }\end{array}$ & $\begin{array}{l}\text { Opportunities for pleasurable sunbathing, visual stimulation, perceived potential } \\
\text { predators (e.g. birds) and control over response (e.g. ability to escape/hide). }\end{array}$ \\
\hline & & $\begin{array}{l}\text { Variety of enclosure substrates to ensure space is } \\
\text { fully utilised. }\end{array}$ & $\begin{array}{l}\text { - Natural (safe) branches of various diameters and orientations to encourage natural } \\
\text { gnawing. Include bark when possible as this is eagerly removed! }\end{array}$ \\
\hline & & & $\begin{array}{l}\text { - Large horizontal areas allow grooming, and alternative area to sleep from nest box } \\
\text { (best if higher in enclosure for sleeping, and urine can drain). }\end{array}$ \\
\hline & & & $\begin{array}{l}\text { - Vet bed/dishcloth hammocks allow play, comfortable resting places and tactile } \\
\text { stimulation. }\end{array}$ \\
\hline & & & $\begin{array}{l}\text { - Vertical branches to allow clinging and leaping, including to the ground level to } \\
\text { encourage use through secure escape if startled. A wooden picnic table is very } \\
\text { effective in providing secure escape routes as well as opportunities for social in- } \\
\text { teraction, if space allows. }\end{array}$ \\
\hline & & & $\begin{array}{l}\text { - Rubber matting/wooden trellis to cover smooth enclosure walls to increase useable } \\
\text { space. }\end{array}$ \\
\hline & & & $\begin{array}{l}\text { - Substrates hung from roof which move to provide unpredictability to encourage } \\
\text { balance. }\end{array}$ \\
\hline & & & - Sawdust, deep litter, bark or other floor covering to encourage foraging. \\
\hline & & Localised additional heat and/or light. & Opportunities to choose preferred light or shade, and temperature for "sun bathing". \\
\hline \multirow[t]{5}{*}{ Social } & \multirow[t]{2}{*}{ Contact } & $\begin{array}{l}\text { Breeding group, or compatible group (preferably re- } \\
\text { lated if same sex), or opposite sexed pairs (breeding pre- } \\
\text { vented using contraception or vasectomy if required). }\end{array}$ & $\begin{array}{l}\text { Caring for infants is natural and time consuming. Groups give security through numbers } \\
\text { and social support. Opportunities for affiliation (e.g. grooming and play). }\end{array}$ \\
\hline & & $\begin{array}{l}\text { Positive interactions with humans, such as hand feed- } \\
\text { ing, positive reinforcement training. }\end{array}$ & $\begin{array}{l}\text { Improved ability to cope with challenges through loss of fear of humans; achievement, } \\
\text { and perceived control from training. }\end{array}$ \\
\hline & \multirow[t]{3}{*}{ Non-contact } & Peep-hole to neighbouring group. & $\begin{array}{l}\text { Opportunity to view marmosets in an adjacent enclosure. Non-contact and lack of } \\
\text { response reduces possibility of redirected aggression, but provides meaningful visual } \\
\text { stimulation. }\end{array}$ \\
\hline & & $\begin{array}{l}\text { Olfactory stability by maintaining own scent-marked } \\
\text { substrates in enclosure following cleaning, and stimu- } \\
\text { lation by introduction/access to others' scents. }\end{array}$ & Environmental stability, together with species-relevant conspecific olfactory novelty. \\
\hline & & $\begin{array}{l}\text { Auditory play back of affiliative chirp vocalisations at a } \\
\text { natural rate. }\end{array}$ & Increasing affiliative interactions through ecologically relevant auditory stimulation. \\
\hline \multirow[t]{7}{*}{ Food } & \multirow[t]{4}{*}{$\begin{array}{l}\text { Novelty, variety, } \\
\text { processing, presentation }\end{array}$} & Vary type of food and location. & Pleasure in taste of food; positive utilisation of environment. \\
\hline & & $\begin{array}{l}\text { Whole fruits and vegetables speared on bamboo, or } \\
\text { hanging on a string. }\end{array}$ & Natural foraging adaptations, physical exercise and balance. \\
\hline & & $\begin{array}{l}\text { Artificial gum tree - syringe gum into holes drilled in } \\
\text { wood. }\end{array}$ & $\begin{array}{l}\text { Natural foraging adaptations, physical exercise. A simpler solution is to offer gum in } \\
\text { paper cups, hooked inside the enclosure. }\end{array}$ \\
\hline & & Insect (e.g. cricket) or meal worm dispensers. & $\begin{array}{l}\text { Natural foraging adaptations and movement requiring hand-eye coordination. Unpre- } \\
\text { dictable access to crickets/mealworms as they naturally drop from dispenser, and have } \\
\text { to be caught. }\end{array}$ \\
\hline & \multirow[t]{3}{*}{$\begin{array}{l}\text { Frequency, scheduling and } \\
\text { predictability }\end{array}$} & $\begin{array}{l}\text { Several meals spread out throughout the day - may in- } \\
\text { clude hand feeding. }\end{array}$ & $\begin{array}{l}\text { Occupies time more usefully and reduces boredom, } \\
\text { reflecting the natural feeding patterns. }\end{array}$ \\
\hline & & $\begin{array}{l}\text { Timing - gum is usually eaten early morning and before } \\
\text { retiring. }\end{array}$ & Natural adaptations; may assist with digestion overnight. \\
\hline & & $\begin{array}{l}\text { Conveyor belt outside cage so food occasionally moves } \\
\text { across it, and the monkeys have to "catch" it. }\end{array}$ & Unpredictability of food simulating insect foraging, movement, eye-hand coordination. \\
\hline \multirow[t]{3}{*}{$\begin{array}{l}\text { Cognitive/ } \\
\text { occupational }\end{array}$} & \multirow[t]{2}{*}{ Puzzles, novel objects } & $\begin{array}{l}\text { Novel objects and furnishings that respond to the mar- } \\
\text { mosets in some way - e.g. feathers, cardboard tubes, } \\
\text { dishcloth hammocks. Rotate objects so they remain } \\
\text { novel. }\end{array}$ & $\begin{array}{l}\text { Perceived control through contingency of behaviour and object response. Exploration - } \\
\text { challenge to work out properties of object, unpredictable movement. }\end{array}$ \\
\hline & & $\begin{array}{l}\text { Cooperative device - two individuals are required to si- } \\
\text { multaneously pull to access food (or other resource). }\end{array}$ & Challenge, social cooperation (appropriate for cooperative primates!), and achievement. \\
\hline & $\begin{array}{l}\text { Positive reinforcement } \\
\text { training session }\end{array}$ & $\begin{array}{l}\text { Training for neutral, but useful husbandry tasks, such as } \\
\text { in-home cage weighing, collar cleaning or vet inspec- } \\
\text { tion (e.g. of body parts) obviates the need for capture. }\end{array}$ & $\begin{array}{l}\text { Perceived control and achievement; occupies time more usefully; } \\
\text { helps to deal with challenges better. }\end{array}$ \\
\hline Sensory & $\begin{array}{l}\text { Visual, auditory, } \\
\text { olfactory, tactile }\end{array}$ & See examples above. & Sensory stimulation is an enrichment goal itself. \\
\hline
\end{tabular}


is difficult to quantify complexity (Sambrook and BuchananSmith, 1997), enclosures for primates in laboratories are obviously less complex than their natural environments. We should be aware that not all aspects of complexity in the wild is good (e.g., inclement weather, predators), and in the laboratory we select the positive aspects of complexity to mimic (e.g., physical and social complexity). A consequence of lack of complexity is an increase in predictability of stimulation, which often leads to boredom. Therefore, environmental complexity and predictability are inversely related; when one declines, the other usually increases. Consequently, an abrupt increase in environmental complexity is not desirable, as high levels of unpredictability may lead to tension and stress (Buchanan-Smith, 1997a; Chamove and Anderson, 1989).

Novelty is a key aspect of complexity, but it is known to be both enriching and stressful, depending upon what is novel and how much control animals have in responding to it. Novelty is also time-limited; animals learn the properties of the object/environment rendering it familiar and no longer novel. The rate of this learning of the properties and hence continued interest in the object/environment will depend upon a number of factors such as complexity, predictability and responsiveness.

There is good evidence that more complex environments have a positive impact on the behaviour and welfare in a range of primate species (e.g., Jensvold et al., 2001; Kerl and Rothe, 1996; Kitchen and Martin, 1996). As well as the positive behavioural effects, Kozorovitskiy et al. (2005) found the biochemical structure of the brain of common marmosets was enhanced, after only one month in a more complex, enriched environment. However, doubling the size of the enriched cage did not elicit further physical changes. This backs up the arguments that it is complexity of the cage that is important, not its size per se (e.g., Badihi et al., 2007; Buchanan-Smith, 1997a; Kerl and Rothe, 1996; Novak, 1989; Poole, 1990). Complexity is such a broad concept it can be applied to all categories in Fig. 1.

\subsection{Choice}

Complexity and choice are closely related, and therefore both complexity and choice are more limited in captivity compared to the wild. What is critical about choice in relation to welfare is that there is pleasure to be gained in the act of choosing, and the very fact that choice exists allows the animals to control a major part of its environment based solely upon its desire at any given time. So, for example, choice of substrates for primates may have an underlying motivation of comfort, to sun on a perch, and then then move to the shade to rest on a cooler substrate, such as rubber matting. Research on primates however, is limited to identifying what primates prefer, rather than the effects of choice or the motivations underlying choice. For example, Pines and his colleagues (2007) allowed common marmosets to choose between indoor and outdoor, and between small and large indoor cages gaining information on the monkeys' preferences (together with the effects of these preferences on their behaviour). Marmosets choose the smaller outside cages over larger inside cages. This may be due to the greater complexity outdoors (e.g., climatic changes, visual stimulation) than indoors together with opportunities to engage in insect foraging. What the researchers do not explore are the welfare benefits of such choice; to do so they would need to determine if the marmosets behaved differently in the outdoor enclosure when there was a choice to be elsewhere, rather than having no choice to be there. Such research on enclosure choice has been conducted on giant pandas (Owen et al., 2005) and illustrates that choice is important.

The provision of choice for captive primates may have many benefits (Hutchinson, 2005), many of which are linked to complexity. Choice allows individuals to have an alternative place to rest (play, run, sit, eat or any other activity) if the usual resting place is occupied (potentially by a dominant individual). Individual preferences will vary, and preferred options may change. Choice may also reduce boredom through exercising the mind. As Markowitz (1982, p. 197) said "we should leave as many decisions as possible to the animals" to increase their behavioural opportunities. Finally, an important aspect of choice for animals is that there is perceived control. For care staff, the provision of choice means that they do not need to invest time in identifying each individual's need, although careful observation must continue to ensure the choices offered are appropriate.

Choice and control are so closely inter-linked in most captive situations that they are identical. When we increase complexity, in physical, social, food, cognitive or sensory domains, we are also increasing the choices available, and vice versa.

\subsection{Control}

Control is difficult to define. In an attempt to enable the measurement of control, Sambrook and Buchanan-Smith (1997, p. 208) offered this operational definition: “... the difference in likelihood of an event occurring depending on an animal's behaviour. If the animal's behaviour does not influence the likelihood of the event then the event deemed uncontrollable." As with complexity and choice, control is diminished in captive environments (Carlstead, 1996; Chamove and Anderson, 1989), while the main adaptive aspect of behaviour is the ability to control (Sambrook and Buchanan-Smith, 1997). As such, many researchers have highlighted that control is critical to good welfare (e.g., Barber and Kuhar, 2006; Bayne, 1989; Buchanan-Smith, 1997b; Line et al., 1990; Rosenblum and Andrews, 1995; Scott, 1991; Warburton, 1991).

Control and predictability are inextricably linked - if an animal can control something, he or she can predict that it will happen. Most of the research on controllability has examined control over aversive stimuli (e.g., electric shock), 
and demonstrated that allowing control over aversive events improves the animal's welfare (Overmier et al., 1980). Hanson and co-workers (1976) showed that allowing rhesus monkeys control over high intensity noise, resulted in lower levels of the stress hormone cortisol, relative to a yoked group (that received identical high intensity noise) but had no control. Overmier and Seligman (1967) offered the "Learned helplessness" theory to explain the detrimental outcomes of exposure to uncontrollable aversive events. According to this theory, these detrimental outcomes are the consequence of motivational, cognitive, and emotional deficits due to prolonged exposure to noncontingent (uncontrollable) events. Positive reinforcement training is one way to increased perceived control as the animal learns to cooperate (Bassett and Buchanan-Smith, 2007).

As enrichment is more focussed on adding positive elements rather than removing or minimising negative elements, we should explore control over positive events, such as control over the delivery of food, over novel objects, visual and auditory stimulation. Providing control over the delivery of food, water and treats improved the behaviour of rhesus macaque peer-reared infants. They increased their exploratory behaviour, coped better when separated from peers, and displayed less fear after being subjected to provocative events (Mineka et al., 1986). In a similar study, Roma and co-workers (2006) found that surrogate peer-reared (individually-housed with daily access to peer group) rhesus infants that were given control over food delivery (by lever pressing) were significantly more active (including locomotion and exploratory activities) and exhibited significantly lower cortisol reactivity compared to yoked monkeys, when exposed individually to a novel enriched environment. To emphasise the effect, there was a positive correlation between the amount of lever pressing in the home cage and behavioural activity in the novel environment, whilst cortisol reactivity to the novel environment was negatively correlated. Reinhardt (1993) found that rhesus monkeys preferred to work for their food (i.e. invest an effort in acquiring it), even when the same food was also freely available effortlessly. This behaviour was interpreted as a desire for control.

However, Sambrook and Buchanan-Smith (1997) argued that the animal's tendency to work for their food does not reflect a desire for control, as by performing the behaviour, the likelihood of reward occurring is actually lower than if the animal gets some of the free food available (i.e. some of the time that might be spent eating the freely available food is taken up with performing the behaviour necessary to control its delivery). Instead, contrafreeloading is more likely to be a form of exploration and assessment of potential food sources, that may become more valuable in future (e.g. Inglis and Ferguson, 1986; Inglis et al., 1997). In addition, whilst feeding captive animals in ways that best improve their welfare is critically important, allowing control over feeding has limitations as many captive animals are over- weight. Furthermore, animals may become obsessed with the new feeding opportunity. Markovitz and Line (1989) found that rhesus macaques would touch a control switch several thousand times to receive a food reward. The desirability of such behaviour is questionable, and it could be considered as another type of stereotypic behaviour (Sambrook and Buchanan-Smith, 1997).

Research on control over novel objects has shown that primates prefer objects that they can control, or in other words, objects that respond to their actions towards it (e.g., by making a noise), or are manipulable (Sambrook and BuchananSmith, 1996; Videan et al., 2005; Vick et al., 2000). Line and co-workers (1990, 1991; Markowitz and Line, 1989) found the behaviour of adult rhesus macaques improved (a significant decrease in negative or undesirable behaviour patterns, such as cage manipulation, abnormal behaviour and autogrooming) when they were given control over food and a radio set (turning it on and off) through manipulation of a device. These monkeys also exhibited lower cortisol levels and heart rate values in response to restraint, and a faster return to normal heart rate value after restraint. The welfare of common marmosets given control over additional illumination in their enclosure improved compared to yoked groups who received the same increases in illumination but no control (Badihi, 2006).

\section{Losing control}

Despite the positive effects of having control, one must take care with the choice of environmental elements that one gives primates control over. Think about what it is like when someone else is channel flicking through television programmes! One of the difficulties in providing captive animals with a device that controls environmental variables (such as music or television with the sound on) is that often only one member of the group controls the device, and all other group members are affected by the stimuli. The same problem affects primates housed in a colony room. If the control over the stimuli is given to members of only one cage, other individuals within the colony room have no ability to control it, which may be detrimental to their welfare (Buchanan-Smith, 1997a).

Furthermore, you should be aware of the potential effects of loss of control - when the controllable device is removed, or the primate is transferred to another facility. Losing control has negative consequences especially for loss of control over negative stimuli (e.g., Mineka and Hendersen, 1985). When rhesus monkeys lost control over high intensity noise, cortisol levels were significantly higher than when the same animals had control over the noise, and than monkeys who never had control over the noise (Hanson et al., 1976). Although no work has been done on the loss of control over positive events in primates, Zimmerman and Koene (1998) showed that loss of controllability over light and food led to higher levels of gakel-calls (which indicate frustration) in 
laying hens, compared to control sessions. In contrast, Hodgson and Bond (1994) did not find any significant differences in the behaviour of rats that were exposed to loss of control over food delivery to that of individuals who were exposed to uncontrollable food delivery.

The links between complexity, choice and control (and their relationship with predictability) are extremely complicated, but the review serves to highlight the importance of each, and the negative consequences of their removal. The final section highlights how such concepts should be put into practice, dependent upon species adaptations.

\section{Making enrichment relevant: concept to practice}

Planning enrichment must involve clearly defining the goals and considering how the intended enrichment will relate to the concepts underlying successful enrichment. A thorough understanding of the natural history of primates in your care is absolutely vital to planning relevant enrichment. As critical for success is ensuring all members of the team are empowered and involved in the enrichment programme. Enrichment should not be an add on to daily husbandry routines, but a vital part of primate care (Rennie and Buchanan-Smith, 2006a). Enrichment initiated by a single person, however well meant, usually fails. The animals may suffer when the individual is on holiday, or ill, due to loss of enrichment, and the number of primates that one individual can enrich is fewer if there is only one person delivering enrichment. Having a team that includes involvement of all care staff (who are often the instigators of such programmes given the satisfaction they gain from improving welfare), named animal care and welfare officers, veterinarians, scientists, as well as the facility inspectors, is the key to success. Sharing ideas, and the positive changes resulting from such programmes is important for momentum. It is also important to ensure the enrichment does not interfere with scientific output (see Sect. 4), and for food enrichment care must be taken to ensure the nutritional content (including calories) is appropriate.

Table 2 gives examples of enrichment that are based on a good understanding of natural history, and hence are ecologically relevant for common marmosets. Evidence of the importance of understanding natural history comes from examples of where the enrichment has not been relevant and hence has met with limited success. One example is the addition of scent to an enclosure (e.g., Ostrower and Brent, 1997; Wells et al., 2007). Scent in the wild is used because it is informative. In marmosets and tamarins the chemical signals deposited are important for communication as they contain useful information on individual identity, rank and reproductive status, they play a role in reproductive competition, and may also aid territorial defence, inter-group spacing and provide cues as to mate quality for marmosets and tamarins. Scent may also play a role in leading animals to food, informing them of ripeness, or warning them of predators (e.g., Buchanan-Smith et al., 1993; Buchanan-Smith, 2010). Simply providing a scent that has no meaning is therefore unlikely to change behaviour in a positive way for long periods. If scent alone was enriching, we may spend considerable time simply sniffing perfumes/aftershaves from the bottle! Rather we are more interested in scent when it is associated and provides clues to a person or informs us of the location or tastiness of food! In a similar way, for scent enrichment to be effective for primates, it needs to be put in a meaningful context in relation to natural history. For example capuchins will enthusiastically rub smelly objects on themselves, as it is a natural behaviour with the potential for insect repelling purposes (Fragaszy et al., 2004).

A similar case could be made for television or auditory "enrichment". To use the latter as an example, we should remember that what is music to humans may simply be an unpleasant noise to non-humans. Indeed music is not received in the same way by all humans; given my background I enjoy listening to the Scottish bagpipes (in the distance) but I realise it is not to everyone's taste! In laboratories where primates are involved in procedures that may make them feel unwell (e.g., in some toxicology, following surgical procedures), such noise may act as an additional stressor over which they have no control. Evidence to back up the lack of positive effect of music comes from a study on the effects of recorded harp music on African Green monkeys (Chlorocebus aethiops). There were no beneficial effects on heart rate, mean blood pressure, respiratory rate, and body temperature (Hinds et al., 2007). Furthermore, McDermott and Hauser (2007) showed that cotton-top tamarins (Saguinus oedipus) preferred slow tempo to fast tempo music, but overall they preferred silence! Even attempts to play natural sounds have met with limited success. Rainforest sounds played to adult lowland gorillas (Gorilla gorilla) resulted in the infants spending less time clinging (and the authors regarded this as positive) whilst there was increased agitation in the adults, considered to be negative (Ogden et al., 1994). However, there are some studies that have found positive effects of auditory stimulation in laboratories. Howell et al. (2003) found that when chimpanzees were played music, loud enough that the lyrics and melody could be heard, they showed less active behaviours including aggression, agitated behaviours and exploratory behaviours and more affiliative behaviours like grooming. Rhesus macaques have also been found to engage in more affiliative behaviour when played jazz music (Novak and Drewsen, 1989) and O'Neill (1989) noted that abnormal behaviours including stereotypical behaviours and self-mouthing, were reduced. Part of the accrued benefits may come from masking other laboratory sounds (Rennie and Buchanan-Smith, 2006b) which act as unreliable signals to events, and such unreliability is known to have negative welfare effects (Bassett and Buchanan-Smith, 2007). Such sounds intended to mask aversive noises in the laboratory may also inadvertently mask communications between 
conspecifics (Newberry, 1995), the effects of which are likely to be dependent on the nature of the communications that are masked. I would argue that the most likely benefits of auditory enrichment will come from more meaningful sound. For example, Watson et al. (2010) played back natural conspecific chirp vocalisations to common marmosets, at a naturally occurring frequency. These chirps are known to be associated with an increase in the affiliative behaviour of individuals in other social groups "the neighbour effect". The playback also resulted in a significant increase in affiliation, and is a promising and cost-effective way to improve the welfare of animals.

\section{Summary and conclusions}

Environmental enrichment is an integral part of the 3Rs, and must become part of the daily routines of care staff. Enrichment not only benefits the welfare of primates, but may also have positive effects on scientific output. As primates ourselves, we share a similar sensory world to our non-human primate cousins, although there are considerable and important differences that we must be aware of. For example some primates can hear sounds we cannot, some have a better developed olfactory sense, and vision in primates can range from monochromatic (black and white), dichromatic (colloquially colour blind, but effectively having difficulty in discriminating between reds, oranges, browns and greens) and trichromatic (having vision similar to our own; BuchananSmith, 2005). None-the-less, the same basic concepts underlying enrichment can also be applied to ourselves to improve our welfare. We share the same needs of security, complexity, opportunities for achievement and novelty. By working out ways to enrich our primates we may be (possibly inadvertently) empowering ourselves, reducing the boredom that comes with routine, getting satisfaction from learning more about the natural history of our primates, enjoy devising enrichment and fulfilling our enrichment goals of enhancing the welfare of primates in our care.

Acknowledgements. I thank Inbal Badihi for her influence in my thinking of the 3Cs (Complexity, Choice and Control), and Valerie Hare, Lou Tasker and Eckhard Heymann for very helpful comments on a draft of the paper. I have listed enrichment ideas from the many primate laboratories I have visited, and I thank my colleagues for being so willing to share ideas.

Edited and reviewed by: E. W. Heymann

\section{References}

Badihi I (2006) The effects of complexity, choice and control on the behaviour and the welfare of captive common marmosets (Callithrix jacchus) [PhD thesis]. Stirling: University of Stirling

Badihi I, Buchanan-Smith HM (2005) Anticipatory behaviour - a new indicator of the significance of environmental enrichment in laboratory-housed common marmosets. Am J Primatol 66 (suppl 1): 178

Badihi I, Morris K, Buchanan-Smith HM (2007) The effects of complexity and choice, together with the loss of them, on the behaviour of a family group of common marmosets (Callithrix jacchus). Lab Prim Newsl 46(4):1-5

Baer JK (1998) A veterinary perspective of potential risk factors in environmental enrichment. In: Shepherdson DJ, Mellen JD, Hutchins M (eds) Second nature: environmental enrichment for captive animals. Washington: Smithsonian Institution Press. p 277-301

Barber J, Kuhar C (2006) Keeping birds in bushes, not in hands: the use of cognitive tasks as individually paced enrichment. In: Proceedings of the Seventh International Conference on Environmental Enrichment, 31 July-5 August 2005, New York. p 15-20

Bassett L, Buchanan-Smith HM, McKinley J, Smith TE (2003) Effects of training on stress-related behavior of the common marmoset (Callithrix jacchus) in relation to coping with routine husbandry procedures. J Appl Animal Wel Sci 6:221-233

Bassett L, Buchanan-Smith HM (2007) Effects of predictability on the welfare of captive primates. Appl Anim Beh Sci 102:223-245

Bateson M (2004) Mechanisms of decision-making and the interpretation of choice tests. Anim Welfare 13 (suppl 1):115-120

Bayne KAL (1989) Environmental enrichment alternatives for laboratory nonhuman primates. In: Driscoll JW (ed) Animal care and use in behavioral research: regulations, issues and applications. Beltsville, Maryland: United States Department of Agriculture. p 91-102

Bekoff M (2002) Animal reflections. Nature 419:255

Benefiel AC, Dong WK, Greenough WT (2005) Mandatory "enriched" housing of laboratory animals: the need for evidencebased evaluation. ILAR J 46:95-105

BHAG (Behavior and Husbandry Advisory Group) (1999) Workshop of the Scientific Advisory Group of the American Zoo and Aquarium Association held at Disney's Animal Kingdom

Bloomsmith MA, Brent LY, Schapiro SJ (1991) Guidelines for developing and managing an environmental enrichment program for nonhuman primates. Lab Anim Sci 41:372-377

Broom DM (2010) Cognitive ability and awareness in domestic animals and decisions about obligations to animals. Appl Anim Behav Sci 126:1-11

Buchanan-Smith HM (1997a) Environmental control: an important feature of good captive callitrichid environments. In: Pryce C, Scott L, Schnell C (eds) Marmosets and tamarins in biological and biomedical research. Salisbury, UK: DSSD Imagery. p 4753

Buchanan-Smith HM (1997b) Considerations for the housing and handling of New World primates in the laboratory. In: Reinhardt $\mathrm{V}$ (ed) Comfortable quarters for laboratory animals. Washington, DC: Animal Welfare Institute. p 75-84

Buchanan-Smith HM (2005) Recent advances in color vision research. Am J Primat 67:393-398 
Buchanan-Smith HM (2010) Marmosets and tamarins. In: Hubrecht RC, Kirkwood J (eds) The UFAW handbook on the care and management of laboratory and other research animals. Chichester: Wiley-Blackwell. p 543-563

Buchanan-Smith HM, Anderson DA, Ryan CW (1993) Response of cotton-top tamarins (Saguinus oedipus) to faecal scents of predators and non-predators. Anim Welfare 2:17-32

Buchanan-Smith HM, Prescott MJ, Cross NJ (2004) What factors should determine cage sizes for primates in the laboratory? Anim Welfare 13 (suppl 1):197-201

Buchanan-Smith HM, Rennie AE, Vitale A, Pollo S, Prescott MJ, Morton DB (2005) Harmonising the definition of refinement. Anim Welfare 14:379-384

Carlstead K (1996) Effects of captivity on the behavior of wild mammals. In: Kleiman DG, Allen ME, Thompson KV, Lumpkin $\mathrm{S}$ (eds) Wild mammals in captivity: principles and techniques. Chicago: University of Chicago Press. p 317-333

Chamove AS, Anderson JR (1989) Examining environmental enrichment. In: Segal E (ed) Psychological well-being of primates. Philadelphia: Noyes. p 183-202

Cooper JJ, Mason GJ (2000) Increasing costs of access to resources cause re-scheduling of behaviour in American mink (Mustela vison): implications for the assessment of behavioural priorities. Appl Anim Behav Sci 66:135-151

Cooper JJ, Mason GJ (2001) The use of operant technology to measure behavioral priorities in captive animals. Behav Res Meth Instrum \& Comp 33:427-434

Crabbe JC, Wahlsten D, Dudek BC (1999) Genetics of mouse behaviour: interactions with laboratory environment. Science 284:1670-1672

Dawkins MS (2004) Using behaviour to assess animal welfare. Anim Welfare 13 (suppl 1):3-7

Dunbar RIM, Schultz S (2007) Understanding primate brain evolution. Phil Trans R Soc B 362:649-658

Erwin J (1979) Aggression in captive macaques: Interaction of social and spatial factors. In: Erwin J, Maple TL, Mitchell G (eds). Captivity and behavior: primates in breeding colonies, laboratories, and zoos. New York: Van Nostrand Reinhold. p 139-171

Eskola S, Lauhikari M, Voipio HM, Laitinen M, Nevalainen T (1999) Environmental enrichment may alter the number of rats needed to achieve statistical significance. Scand J Lab Anim Sci 26:134-144

Etheridge MA, O’Malley J (1996) Diarrhea and peritonitis due to traumatic perforation of the stomach in a rhesus macaque (hardware disease). Contemp Topics Lab Anim Med 35:57-58

FELASA (Federation of European Laboratory Animal Science Associations) (2006) FELASA Working Group on Standardization of Enrichment Working Group Report. Available at: http: //www.lal.org.uk/

Fragaszy DM, Visalberghi E, Fedigan LM (eds) (2004) The complete capuchin: The biology of the genus Cebus. Cambridge: Cambridge University Press

Francis DD, Diorio J, Plotsky PM, Meaney MJ (2002) Environmental enrichment reverses the effects of maternal separation on stress reactivity. J Neurosci 22:7840-7843

Garner JP (2005) Stereotypies and other abnormal repetitive behaviors: potential impact on validity, reliability, and replicability of scientific outcomes. ILAR J 46:106-117
Hahn NE, Lau D, Eckert K, Markowitz H (2000) Environmental enrichment- related injury in a macaque (Macaca fascicularis): Intestinal linear foreign body. Comp Med 50:556-558

Hansen SW, Jeppesen LL (2006) Temperament, stereotypies and anticipatory behaviour as measures of welfare in mink. Appl Anim Beh Sci 99:172-182

Hanson JD, Larson ME, Snowdon CT (1976) The effects of control over high intensity noise on plasma cortisol levels in rhesus monkeys. Behav Biol 16:333-340

Hediger H (1950) Wild animals in captivity: an outline of the biology of zoological gardens. New York: Dover Publications

Hinds SB, Raimond S, Purcell BK (2007) The effect of harp music on heart rate, mean blood pressure, respiratory rate, and body temperature in the African green monkey. J Med Primat 36:95100

Hodgson DM, Bond NW (1994) The role of loss of control and predictability in the hypoalgesic response to noncontingent food delivery in rats. Psychobiol 22:232-237

Honess PE, Marin CM (2006) Enrichment and aggression in primates. Neurosci \& Biobehav Rev 30:413-436

Howell S, Schwandt M, Fritz J, Roeder E, Nelson C. (2003) A stereo music system as environmental enrichment for captive chimpanzees (Pan troglodytes). Lab Anim 32:31-36

Hubrecht RC (2010) Enrichment: Animal welfare and experimental outcomes. In: Hubrecht RC, Kirkwood J (eds) The UFAW handbook on the care and management of laboratory and other research animals. Chichester: Wiley-Blackwell. p 136-146

Hubrecht R, Kirkwood J (eds). (2010) The UFAW handbook on the care and management of laboratory and other research animals. Chichester: Wiley-Blackwell

Hutchinson JMC (2005) Is choice always desirable? Evidence and arguments from leks, food selection, and environmental enrichment. Biol Rev 80:73-92

Inglis IR, Ferguson NJK (1986) Starlings search for food rather than eat freely-available, identical food. Anim Behav 34:614-617

Inglis IR, Forkman B, Lazarus J (1997) Free food or earned food? A review and fuzzy model of contrafreeloading. Anim Behav 53:1171-1191

JWGR (Joint Working Group on Refinement) (2009) Refinements in husbandry, care and common procedures for non-human primates: 9th report of the BVAAWF/FRAME/RSPCA/UFAW Joint Working Group on Refinement (M Jennings \& MJ Prescott, eds). Lab Anim 43 (Suppl 1):1-47

Jensvold MLA, Sanz CM, Fouts RS, Fouts DH (2001) Effect of enclosure size and complexity on the behaviors of captive chimpanzees (Pan troglodytes). J Appl Anim Wel Sci 4:53-69

Kerl J, Rothe H (1996) Influence of cage size and cage equipment on physiology and behavior of common marmosets (Callithrix jacchus). Lab Prim Newsl 35(3):10-13

Kitchen AM, Martin AA (1996) The effects of cage size and complexity on the behaviour of captive common marmosets, Callithrix jacchus jacchus. Lab Anim 30:317-326

Kozorovitskiy Y, Gross CG, Kopil C, Battaglia L, McBreen M, Stranahan AM, Gould E (2005) Experience induces structural and biochemical changes in the adult primate brain. Proc Nat Acad Sci USA 102:17478-17482

Line SW, Clarke AS, Markowitz H, Ellman G (1990) Responses of female rhesus macaques to an environmental enrichment apparatus. Lab Anim 24:213-220 
Line SW, Markowitz H, Morgan KN, Strong S (1991) Effects of cage size and environmental enrichment on behavioral and physiological responses of rhesus macaques to the stress of daily events. In: Novak MA, Petto AJ (eds). Through the looking glass, Washington, DC: American Psychological Association. 160-179

Lutz C, Well A, Novak M (2003) Stereotypic and self-injurious behaviour in rhesus macaques: a survey and retrospective analysis of environment and early experience. Am J Primatol 60:1-15

Markowitz H (1982) Behavioral enrichment in the zoo. New York: Van Nostrand Reinhold

Markowitz H, Line S (1989) Primate research models and environmental enrichment. In: Segal EF (ed) Housing, care and psychological well-being of captive and laboratory primates. Park Ridge, NJ: Noyes Publications. p 203-212

McDermott J, Hauser MD (2007) Nonhuman primates prefer slow tempos but dislike music overall. Cognition 104:654-668

Mendl M, Paul ES (2004) Consciousness, emotion and animal welfare: insights from cognitive science. Anim Welfare 13 (suppl 1):17-25

Mineka S, Gunnar M, Champoux M (1986) Control and early socioemotional development: infant rhesus monkey reared in controllable versus uncontrollable environment. Child Dev 57:12411256

Mineka S, Hendersen R (1985) Controllability and predictability in acquired motivation. Ann Rev Psych 36:495-529

Murchison MA (1993) Potential animal hazard with ring toys. Lab Prim Newsl 32(1):1-2

Nelson RJ, Mandrell TD (2005) Enrichment and nonhuman primates: "First, do no harm". ILAR J 46:171-177

Newberry RC (1995) Environmental enrichment: Increasing the biological relevance of captive environments. Appl Anim Behav Sci 44:229-243

Novak MA (1989) Psychological well-being: applications to social groups of nonhuman primates. In: Driscoll JW (ed) Animal care and use in behavioral research: regulations, issues and applications. Beltsville, Maryland: United States Department of Agriculture. p 81-90

Novak MA, Drewsen KH, (1989) Enriching the lives of captive primates: Issues and problems. In: Segal EF (ed) Housing, care and psychological well-being of captive and laboratory primates. Park Ridge, NJ: Noyes Publications. p 161-182

Ogden JJ, Lindburg DG, Maple TLA (1994) preliminary study of the effects of ecologically relevant sounds on the behaviour of captive lowland gorillas. App Anim Behav Sci 39:163-176

O'Neill PA (1989) room with a view for captive primates: Issues, goals, related research and strategies. In: Segal EF (ed) Housing, care and psychological well-being of captive and laboratory primates. Park Ridge, NJ: Noyes Publications. p 135-160

Ostrower S, Brent L (1997) Olfactory enrichment for captive chimpanzees: Response to different odors. Lab Prim Newsl 36(1):810

Overmier JB, Patterson J, Wielkiewicz RM (1980) Environmental contingencies as sources of stress in animals. In: Levine S, Ursin $\mathrm{H}$ (eds) Coping and health.New York: Plenum Press. p 1-38

Overmier JB, Seligman MEP (1967) Effects of inescapable shock upon subsequent escape learning. J Comp Physiol Psych 63:2833

Owen MA, Swaisgood RR, Czekala NM, Lindburg DG (2005) Enclosure choice and well-being in giant pandas: is it all about con- trol? Zoo Biol 24:475-481

Pines MK, Kaplan G, Rogers LJ (2007) A note on indoor and outdoor housing preferences of common marmosets (Callithrix jacchus). Appl Anim Behav Sci 108:348-353

Poole TB (1998) Meeting a mammal's psychological needs: Basic principles. In: Shepherdson DJ, Mellen JD, Hutchins M (eds). Second nature: environmental enrichment for captive animals. Washington, DC: Smithsonian Institution Press: 83-94

Poole TB (1990) Environmental enrichment for marmosets. Anim Technol 41:81-86

Prescott MJ, Buchanan-Smith HM (2004) Cage sizes for tamarins in the laboratory. Anim Welfare 13:151-157

Primate Enrichment Database: http://labanimals.awionline.org/ SearchResultsSite/enrich.aspx (last access: June 2011)

Pryce CR, Rüedi-Bettschen D, Dettling AC, Weston A, Russig H, Ferger B, Feldon J (2005) Long-term effects of early-life environmental manipulations in rodents and primates: potential animal models in depression research. Neurosci \& Biobehav Rev 29:649-674

Reinhardt V (1993) Enticing nonhuman primates to forage for their standard biscuit ration. Zoo Biol 12:307-312

Rennie AE, Buchanan-Smith HM (2005) Report on the extent and character of primate use in scientific procedures across Europe in 2001. Lab Prim Newsl 44(2):6-12

Rennie AE, Buchanan-Smith HM (2006a) Refinement of the use of non-human primates in scientific research. Part I: The influence of humans. Anim Welfare 15:203-213

Rennie AE, Buchanan-Smith HM (2006b) Refinement of the use of non-human primates in scientific research. Part II: Housing, husbandry and acquisition. Anim Welfare: 15:215-238

Roma PG, Champoux M, Suomi SJ (2006) Environmental control, social context, and individual differences in behavioral and cortisol responses to novelty in infant rhesus monkeys. Child Dev 77:118-131

Rosenblum LA, Andrews MW (1995) Environmental enrichment and psychological well-being of nonhuman primates. In: Bennett T (ed) Nonhuman Primates in Biomedical Research: Biology and Management. New York: Academic Press. p 101-112

Russell WMS, Burch RL (1959, reprinted 1992). The principles of humane experimental technique. Wheathampstead, UK: Universities Federation for Animal Welfare

Sambrook TD, Buchanan-Smith HM (1996) What makes novel objects enriching? A comparison of the qualities of control and complexity. Lab Prim Newsl 35(4):1-4

Sambrook TD, Buchanan-Smith HM (1997) Control and complexity in novel object enrichment. Anim Welfare 6:207-216

Sanchez MM (2006) The impact of early adverse care on HPA axis development: Nonhuman primate models. Horm Behav 50:623631

Schapiro SJ, Kessel AL (1993) Weight gain among juvenile rhesus macaques: A comparison of enriched and control groups. Lab Anim Sci 43:315-318

Schapiro SJ, Bloomsmith MA, Kessel AL, Shively CA (1993) Effects of enrichment and housing on cortisol response in juvenile rhesus monkeys. Appl Anim Behav Sci 37:251-263

Schapiro SJ, Nehete PN, Perlman JE, Sastry KJ (2000) A comparison of cell-mediated immune responses in rhesus macaques housed singly, in pairs, or in groups. App Anim Behav Sci 68:67-84 
Schaffner CM, Smith TE (2005) Familiarity may buffer the adverse effects of relocation on marmosets (Callithrix kuhlii): preliminary evidence. Zoo Biol 24:93-100

Schneider ML, Roughton EC, Koehler AJ, Lubach GR (1999) Growth and development following prenatal stress exposure in primates: an examination of ontogenetic vulnerability. Child Dev 70:263-274

Scott L (1991) Environmental enrichment for single housed common marmosets. In: Box HO (ed) Primate responses to environmental change. London: Chapman \& Hall. p 265-274

Shepherdson DJ (1998) Tracing the path of environmental enrichment in zoos, in: Shepherdson DJ, Mellen JD, Hutchins M (eds). Second nature: environmental enrichment for captive animals. Washington, DC: Smithsonian Institute Press. p 1-12

Sherwin CM (2004) The influences of standard laboratory cages on rodents and the validity of research data. Anim Welfare 13 (suppl 1):9-15

Smith JA, Boyd KM (2002) The Boyd Group papers on "The use of non-Human primates in research and testing". Southsea, UK: The British Psychological Society Scientific Affairs Board Standing Advisory Committee on the Welfare of Animals in Psychology

Spruijt BM, van den Bos R, Pijlman FTA (2001) A concept of welfare based on reward evaluating mechanisms in the brain: anticipatory behaviour as an indicator for the state of reward systems. App Anim Behav Sci 72:145-171

Suomi SJ (1997) Early determinants of behaviour: evidence from primate studies. Brit Med Bull 53:170-184

van de Weerd HA, Aarsen EL, Mulder A, Kruitwagen CLJJ, Hendriksen CFM, Baumans V (2002) Effects of environmental enrichment for mice: variation in experimental results. J App Anim Welf Sci 5:87-109

van der Harst JE, Fermont PCJ, Bilstra AE, Spruijt BM (2003) Access to enriched housing is rewarding to rats as reflected by their anticipatory behaviour. Anim Behav 66:493-504 van der Harst JE, Baars AM, Spruijt BM (2005) Announced rewards counteract the impairment of anticipatory behaviour in socially stressed rats. Behav Brain Res 161:183-189

Veasey JS, Waran NK, Young RJ (1996) On comparing the behaviour of zoo housed animals with wild conspecifics as a welfare indicator. Anim Welfare 5:13-24

Ventura R, Buchanan-Smith HM (2003) Physical environment effects on infant care and infant development in captive common marmosets Callithrix jacchus. Int J Primatol 24:399-413

Vick SJ, Anderson JR, Young, R (2000) Maracas for Macaca? Evaluation of Three Potential Enrichment Objects in Two Species of Zoo-Housed Macaques. Zoo Biol 19:181-191

Videan EN, Fritz J, Schwandt ML, Smith HF, Howell S (2005) Controllability in environmental enrichment for captive chimpanzees (Pan troglodytes). J Appl Anim Welf Sci 8:117-130

Waitt CD, Bushmitz M, Honess PE (2010) Designing environments for aged primates. Lab Prim Newsl 49(3):5-9

Warburton DM (1991) Stress and distress in response to change. In: Box HO (ed) Primate responses to environmental change: London: Chapman and Hall. p 337-356

Watson CFI, Caldwell CA, Buchanan-Smith HM (2010) Can a social culture of increased affiliation be facilitated in captive monkeys through call playback? Primate Eye 101:10

Wells DL, Hepper PG, Coleman D, Challis MG (2007) A note on the effect of olfactory stimulation on the behaviour and welfare of zoo-housed gorillas. Appl Anim Behav Sci 106:155-160

Würbel H (2000) Behaviour and the standardization fallacy. Nature Genetics 26:263

Young RJ (2003) Environmental enrichment for captive animals. Oxford: Blackwell Science

Zimmerman PH, Koene P (1998) The effect of loss of predictability and controllability of reward during frustration on behaviour in two strains of laying hens, Gallus gallus domesticus. Netherl J Zool 48:255-265 